\title{
pH-controlled hydrothermal synthesis of titanium phosphates and their powder properties
}

\author{
Hiroaki ONODA*, Taisuke YAMAGUCHI \\ Department of Informatics and Environmental Sciences, Kyoto Prefectural University, 1-5, Shimogamo \\ Nakaragi-cyo, Sakyo-ku, Kyoto 606-8522, Japan
}

Received: June 24, 2014; Revised: August 12, 2014; Accepted: August 18, 2014

(C) The Author(s) 2014. This article is published with open access at Springerlink.com

\begin{abstract}
Titanium phosphates were prepared from titanium chloride and sodium pyrophosphate at various $\mathrm{pH}$ in hydrothermal process as a novel white pigment for cosmetics. Their chemical composition, powder properties, photo catalytic activity, colour phase and smoothness were studied. The obtained materials had a higher Ti/P ratio than that used in preparation conditions because of the formation of titanium oxide and hydroxide. The samples prepared at $\mathrm{pH}=4$ had particles smaller than $100 \mu \mathrm{m}$. Titanium phosphates had less photo catalytic activity to protect the sebum on the skin. The obtained materials in hydrothermal process and their thermal products at $100{ }^{\circ} \mathrm{C}$ showed high reflectance in the range of visible light.
\end{abstract}

Keywords: titanium phosphates; pyrophosphate; $\mathrm{pH}$; photo catalytic activity; smoothness

\section{Introduction}

As a white pigment, titanium dioxide is used for cosmetic applications [1]. This oxide is well known to have a photo catalytic activity. Therefore, a certain degree of sebum on the skin is decomposed by the ultraviolet radiation in sunlight. To repress this effect, technical processes of several kinds have been investigated and used. For example, as one such technique, composite particles with silicon oxide have been used [2]. However, these particle materials are too hard for use on a human face. Mild materials are required for use as a white pigment on a human face. In addition, one report has described that microfine titanium dioxide is adsorbed through the skin [3]. A novel white pigment that is not adsorbed must be used.

Phosphates have been used for ceramic materials, catalysts, adsorbents, fluorescent materials, dielectric

* Corresponding author.

E-mail: onoda@kpu.ac.jp substances and biomaterials, for metal surface treatment, as fertilizer, detergents and food additives, in fuel cells and pigments, and in other applications [4-8]. Phosphate materials are well known to have high affinity for living organisms. Therefore, as a novel white pigment, phosphates are expected to be useful as cosmetics.

As a pigment for cosmetics, particle shape and size distribution are important. Spherical homogenized particles are expected to spread well on the skin. However, overly small particles are unsuitable because pigments might enter pores in the skin. Hydrothermal processes are generally used to control the powder properties of inorganic phosphate materials [9-11]. The functional materials are obtained from high temperature aqueous solution at high vapor pressure. In earlier studies [12,13], we prepared a titanium phosphate pigment that has no catalytic activity. However, the obtained particles have a wide distribution of $1-300 \mu \mathrm{m}$ in diameter. The $\mathrm{pH}$ value in preparation has influence on the particle shape and size of phosphate materials [14]. Therefore, the present 
work was undertaken to obtain homogenized titanium phosphate particles by changing $\mathrm{pH}$ value.

Phosphates are transformed to other forms of phosphates by hydrolysis and dehydration reactions at elevated temperatures [4]. These condensed phosphates have novel functional properties, because these condensed phosphates have different properties with orthophosphates [5]. Orthophosphates have been investigated for many applications, but condensed phosphates have been little studied [15]. Nevertheless, condensed phosphates can possess high functional properties.

For this work, titanium phosphates were prepared from titanium chloride and sodium pyrophosphate, and then adjusted to various $\mathrm{pH}$, treated in a hydrothermal process. Their respective chemical compositions, powder properties, photo catalytic activity, colour phases and smoothness of the obtained precipitates and their thermal products were studied for application to cosmetics.

\section{Experimental}

Sodium pyrophosphate, $\mathrm{Na}_{4} \mathrm{P}_{2} \mathrm{O}_{7}$, was synthesized by heating disodium hydrogen phosphate, $\mathrm{Na}_{2} \mathrm{HPO}_{4}$, at $400{ }^{\circ} \mathrm{C}$ for $5 \mathrm{~h}$ [16]. The obtained pyrophosphate was determined by high performance liquid chromatography-flow injection analysis (HPLC-FIA). The phosphorus distribution in phosphates was determined with HPLC-FIA from TOSOH Corp. Ltd. The separations were performed on a column $(250 \times$ $4.0 \mathrm{~mm}$ inner diameter) packed with a polystyrenebased anion exchanger (TSK gel SAX, diameter of particle $10 \mu \mathrm{m}$, Toyo Soda). The eluents for the chromatographic separation of phosphates were comprised of appropriate concentrations of potassium chloride and $0.1 \%(w / v) \mathrm{Na}_{4}$ EDTA $(\mathrm{pH}=10)$. The $\mathrm{Mo}(\mathrm{V})-\mathrm{Mo}(\mathrm{VI})$ reagent for the analysis of phosphates was prepared by the method of Lucena-Conde and Prat [17]. The heteropoly blue complex thus formed was detected at $830 \mathrm{~nm}$ in the flow cell.

Glycerin was added to $0.5 \mathrm{~mol} / \mathrm{L}$ in 0.1 phosphorus$\mathrm{mol} / \mathrm{L}$ of the sodium pyrophosphate solution to improve the water retention [12]. Then $0.1 \mathrm{~mol} / \mathrm{L}$ of titanium chloride solution $(140 \mathrm{ml})$ was mixed with the sodium pyrophosphate solution $(280 \mathrm{ml})$ in molar ratio of $\mathrm{Ti} / \mathrm{P}=1 / 2$. This ratio of $\mathrm{Ti} / \mathrm{P}$ was determined from the theoretical chemical composition of $\mathrm{TiP}_{2} \mathrm{O}_{7}$. The mixed solution was adjusted to $\mathrm{pH}=4,7$ and 9 with ammonia solution and stirred for $2 \mathrm{~h}$. Then, the solution was set in the autoclave for $4 \mathrm{~h}, 8 \mathrm{~h}$ and $12 \mathrm{~h}$ at $120{ }^{\circ} \mathrm{C}$ and $100 \mathrm{kPa}$ (hydrothermal treatment). The precipitates were filtered off, washed with water and dried. The chemicals were of guaranteed reagent from Wako Chemical Industries Ltd. (Osaka, Japan) without further purification.

The chemical compositions of these materials were analyzed using X-ray diffraction (XRD). The XRD patterns were recorded on an X-ray diffractometer (MiniFlex; Rigaku Corp.) using monochromated $\mathrm{Cu}$ $\mathrm{K} \alpha$ radiation. Thermogravimetry (TG) and differential thermal analysis (DTA) curves of precipitates were measured (DTG-60A; Shimadzu Corp.) at a heating rate of $10{ }^{\circ} \mathrm{C} / \mathrm{min}$ under air. Samples were heated at $100{ }^{\circ} \mathrm{C}, 200{ }^{\circ} \mathrm{C}$ and $400{ }^{\circ} \mathrm{C}$ in air conditions. These thermal products were also analyzed according to their XRD patterns.

The particle shape and size of the precipitates and their thermal products were estimated from scanning electron microscopy (SEM) images and particle size distributions. SEM images of titanium phosphates were observed (JGM-5510LV; JEOL). The particle size distributions of these materials were measured using laser diffraction/scattering particle size distribution (LA-910; Horiba Ltd.).

The cosmetic properties were estimated according to the photo catalytic activity, colour phase and smoothness. The photo catalytic activity of the samples was estimated with the decomposition of methylene blue by $365 \mathrm{~nm}$ radiation [18,19]. A $0.01 \mathrm{~g}$ portion of the sample was placed in $4 \mathrm{ml}$ of methylene blue solution $\left(1.0 \times 10^{-5} \mathrm{~mol} / \mathrm{L}\right)$; this solution was then irradiated. The decrease in the absorption at about $660 \mathrm{~nm}$ was evaluated over the course of $120 \mathrm{~min}$. The colour of phosphate pigments was estimated using ultraviolet-visible (UV-Vis) reflectance spectra with a spectrophotometer (UV2100; Shimadzu Corp.). The particle smoothness was measured on artificial leather with KES-SE objective evaluation of surface friction property (Kato Tech Co. Ltd.).

\section{Results and discussion}

\subsection{Chemical composition of precipitates}

Table 1 shows the Ti/P ratios of samples prepared under various conditions. Precipitate was not obtained at $\mathrm{pH}=9$ in hydrothermal treatment for $4 \mathrm{~h}$. All 
samples have higher $\mathrm{Ti} / \mathrm{P}$ ratios than that in preparation condition $(\mathrm{Ti} / \mathrm{P}=1 / 2)$. If the target phosphates were formed, then the Ti/P ratio in precipitates was the same with that in preparation condition. Titanium phosphate powders are regarded as containing titanium oxide or hydroxide. Because, as described later, the samples have less photo catalytic activity, titanium oxide or hydroxide exists at inner part of the particles. The Ti/P ratio is less affected from $\mathrm{pH}$ value and hydrothermal time.

Figure 1 presents XRD patterns of samples prepared at various $\mathrm{pH}$ and then treated in a hydrothermal process for $8 \mathrm{~h}$. All samples have a certain degree of amorphous phase. The sample prepared at $\mathrm{pH}=9$ has unknown peaks. By heating at $400{ }^{\circ} \mathrm{C}$, these peaks disappear. The samples prepared at $\mathrm{pH}=4$ and 7 are amorphous in XRD analysis in spite of the heat treatment at $400{ }^{\circ} \mathrm{C}$. The hydrothermal time also has less influence on the crystalline condition of titanium phosphates.

Figure 2 presents TG curves of samples prepared at various $\mathrm{pH}$ and then treated in a hydrothermal process for $12 \mathrm{~h}$. The weight losses at about $90{ }^{\circ} \mathrm{C}$ and $280{ }^{\circ} \mathrm{C}$ correspond to the volatilization of water and glycerin combustion. The weight losses at $200{ }^{\circ} \mathrm{C}$ are $12.3 \%$,

Table $1 \mathrm{Ti} / \mathrm{P}$ ratios of precipitates prepared in various conditions

\begin{tabular}{cccc}
\hline Sample No. & Hydrothermal time $(\mathrm{h})$ & $\mathrm{pH}$ & $\mathrm{Ti} / \mathrm{P}$ ratio \\
\hline 1 & 4 & 4 & 0.78 \\
2 & 4 & 7 & 1.10 \\
3 & 8 & 4 & 1.14 \\
4 & 8 & 7 & 1.06 \\
5 & 8 & 9 & 1.02 \\
6 & 12 & 4 & 1.13 \\
7 & 12 & 7 & 1.04 \\
8 & 12 & 9 & 1.04 \\
\hline
\end{tabular}

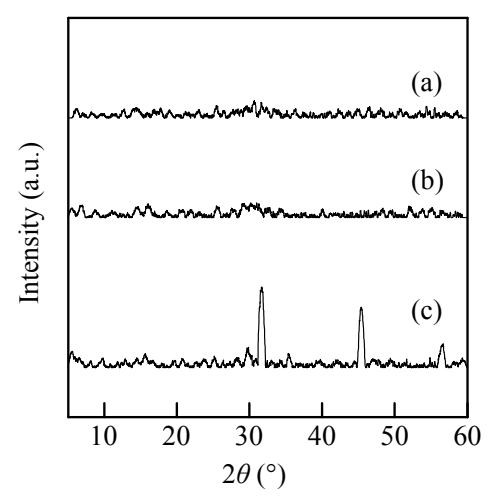

Fig. 1 XRD patterns of samples prepared at various $\mathrm{pH}$ (hydrothermal treatment for $8 \mathrm{~h}$ ): (a) $\mathrm{pH}=4$, (b) $\mathrm{pH}=7$ and (c) $\mathrm{pH}=9$.

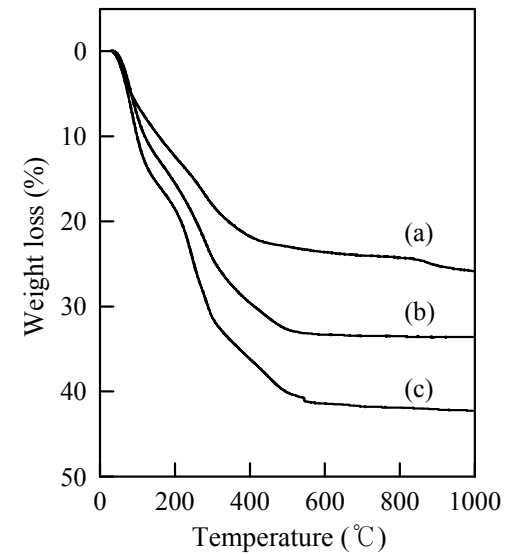

Fig. 2 TG curves of samples prepared at various $\mathrm{pH}$ (hydrothermal treatment for $12 \mathrm{~h}$ ): (a) $\mathrm{pH}=4$, (b) $\mathrm{pH}=7$ and (c) $\mathrm{pH}=9$.

$15.5 \%$ and $18.5 \%$ in samples prepare at $\mathrm{pH}=4,7$ and 9 , respectively. And, the weight losses at $550{ }^{\circ} \mathrm{C}$ are $23.3 \%, 33.2 \%$ and $41.2 \%$ in samples prepared at $\mathrm{pH}=$ 4,7 and 9, respectively. Sample prepared at $\mathrm{pH}=9$ has large amount of water and glycerin.

Figure 3 presents DTA curves of samples prepared at various $\mathrm{pH}$ and then treated in a hydrothermal process for $12 \mathrm{~h}$. The endothermic peaks at about $90{ }^{\circ} \mathrm{C}$ and exothermic peaks at $280{ }^{\circ} \mathrm{C}$ and $710{ }^{\circ} \mathrm{C}$ are observed in DTA curves of samples. These peaks are resulted from the volatilization of water, the combustion of glycerine and the crystallization of materials. The endothermic peaks at $90{ }^{\circ} \mathrm{C}$ and the exothermic peaks at $270{ }^{\circ} \mathrm{C}$ become large in samples prepared at $\mathrm{pH}=7$ and 9 . These changes correspond with the TG results.

\section{2 Powder properties of titanium phosphates}

From the viewpoint of particle shape, spherical particles are suitable for cosmetic applications. Figure 4

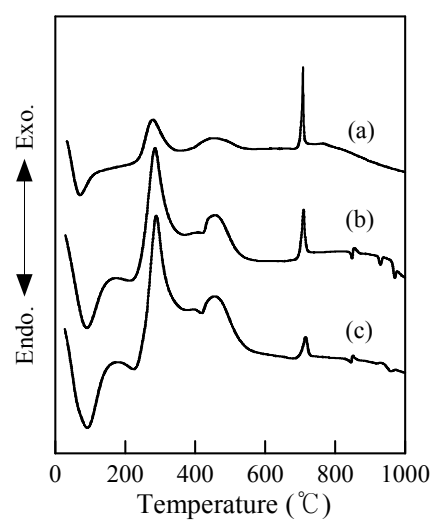

Fig. 3 DTA curves of samples prepared at various $\mathrm{pH}$ (hydrothermal treatment for $12 \mathrm{~h}$ ): (a) $\mathrm{pH}=4$, (b) $\mathrm{pH}=7$ and (c) $\mathrm{pH}=9$. 

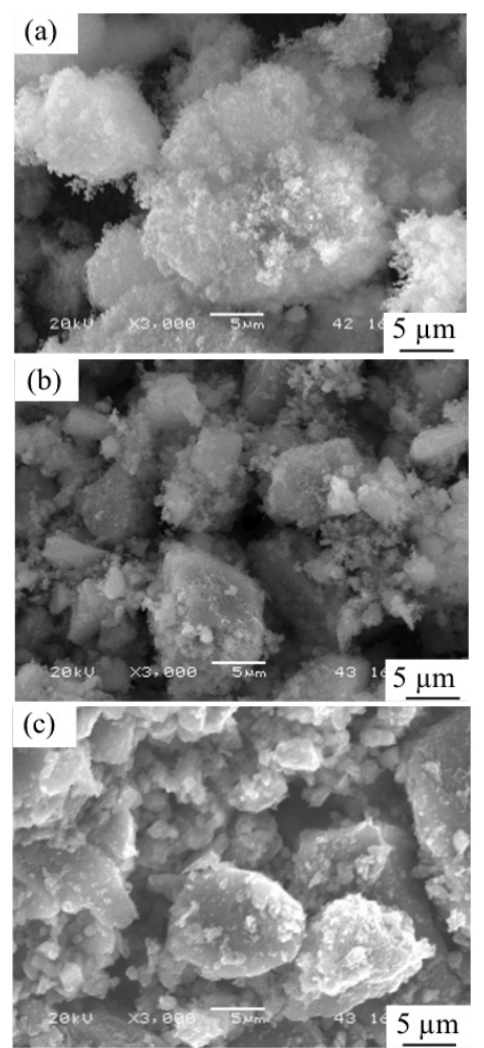

Fig. 4 SEM images of samples prepared at various $\mathrm{pH}$ and then heated at $100{ }^{\circ} \mathrm{C}$ (hydrothermal treatment for $8 \mathrm{~h}$ ): (a) $\mathrm{pH}=4$, (b) $\mathrm{pH}=7$ and (c) $\mathrm{pH}=9$.

portrays SEM images of samples prepared at various $\mathrm{pH}$ and then heated at $100{ }^{\circ} \mathrm{C}$. No specified shape is observed in all samples. The $\mathrm{pH}$ value, heating temperature and hydrothermal time have less influence on particle shape.

Figure 5 presents the particle size distribution of samples prepared at various $\mathrm{pH}$ and then heated at $100{ }^{\circ} \mathrm{C}$ (hydrothermal time $8 \mathrm{~h}$ ). The particle sizes of these samples are $1-500 \mu \mathrm{m}$. Samples prepared at $\mathrm{pH}=4$ have smaller particles than those at $\mathrm{pH}=7$ and 9. A large number of particles have smaller size than $100 \mu \mathrm{m}$ in the sample prepared at $\mathrm{pH}=4$. The heating temperature has less influence on particle size of titanium phosphates. Samples prepared in hydrothermal treatment for $12 \mathrm{~h}$ have similar particle size with those for $8 \mathrm{~h}$. However, samples prepared in hydrothermal treatment for $4 \mathrm{~h}$ have larger particles. The particle size in particle size distribution is corresponding with those in SEM images. Therefore, the obtained phosphate particles are not aggregated.

For cosmetic applications, small and homogeneous particles are suitable. However, overly small particles show difficult shortcoming of entering pores in the skin [3]. The standard size of the white pigment for

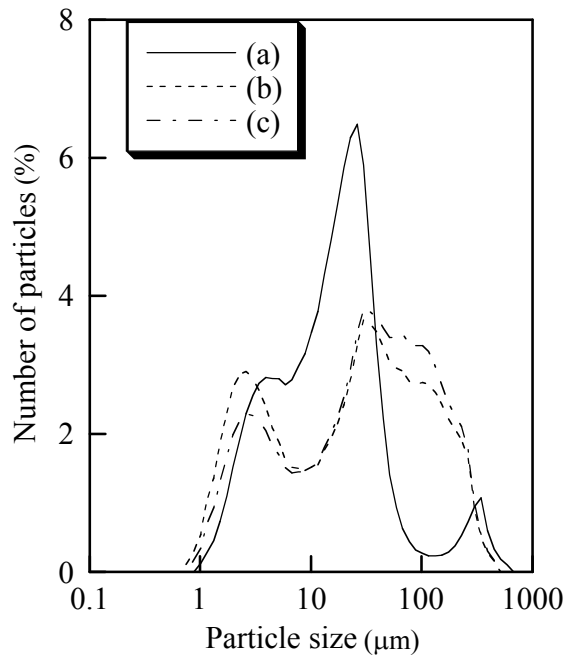

Fig. 5 Particle size distribution of samples prepared at various $\mathrm{pH}$ and then heated at $100{ }^{\circ} \mathrm{C}$ (hydrothermal treatment for $8 \mathrm{~h}$ ): (a) $\mathrm{pH}=4$, (b) $\mathrm{pH}=$ 7 and (c) $\mathrm{pH}=9$.

cosmetics is difficult to determine because the skin pore size is affected by factors such as age, gender and climate. Furthermore, overly large particles are inappropriate because of the cracking of the coating on the skin. It is important to control the pigment particle size. Further studies are required to obtain homogenized spherical particles of titanium phosphate pigments for use in cosmetics.

\section{3 Cosmetic properties of titanium phosphates}

Figure 6 shows the respective photo catalytic activities of samples prepared in various conditions. Because titanium dioxide is used as a white pigment in cosmetics, this compound is evaluated for comparison with uncoated titanium phosphate [1]. Methylene blue is decomposed with titanium dioxide using UV radiation (Fig. 6(b)). Titanium phosphate has little photo catalytic activity in spite of the kinds of $\mathrm{pH}$ value, heating temperature and hydrothermal time (Figs. 6(c)-6(h)). Titanium phosphate is a mild material that can protect the sebum on the skin.

Figure 7 shows UV-Vis reflectance spectra of samples prepared at $\mathrm{pH}=4$ and then heated at several temperatures (hydrothermal time $8 \mathrm{~h}$ ). Samples without heating and those heated at $100{ }^{\circ} \mathrm{C}$ indicate high reflectance in the range of visible light. Samples heated at $200{ }^{\circ} \mathrm{C}$ and $400{ }^{\circ} \mathrm{C}$ show lower reflectance because of the incomplete combustion of glycerin. Heat treatments at $200{ }^{\circ} \mathrm{C}$ and $400{ }^{\circ} \mathrm{C}$ are unsuitable to obtain titanium phosphate white pigments even with $\mathrm{pH}$ and hydrothermal time. 


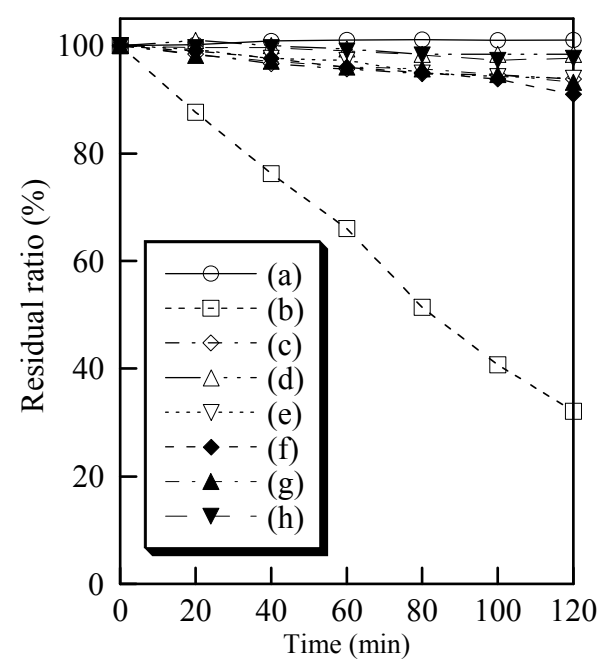

Fig. 6 Photo catalytic activity of samples (hydrothermal treatment for $8 \mathrm{~h}$ ): (a) blank; (b) $\mathrm{TiO}_{2}$; (c) $\mathrm{pH}=4$, room temperature (R.T.); (d) $\mathrm{pH}=7$, R.T.; (e) $\mathrm{pH}=9$, R.T.; (f) $\mathrm{pH}=4,100{ }^{\circ} \mathrm{C}$; (g) $\mathrm{pH}=7$, $100{ }^{\circ} \mathrm{C}$; and (h) $\mathrm{pH}=9,100{ }^{\circ} \mathrm{C}$.

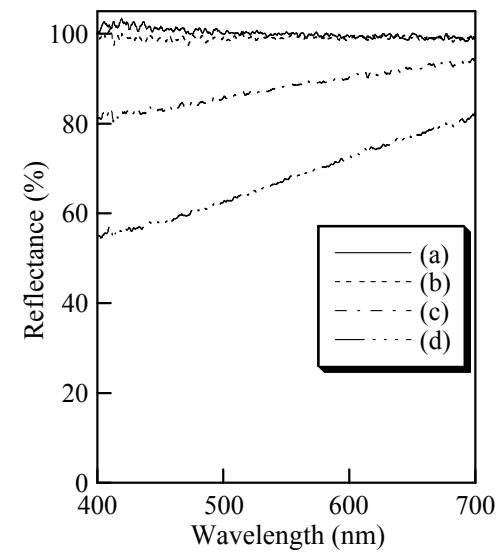

Fig. 7 UV-Vis reflectance spectra of samples prepared at $\mathrm{pH}=4$ and then heated at several temperatures (hydrothermal treatment for $8 \mathrm{~h}$ ): (a) R.T., (b) $100{ }^{\circ} \mathrm{C}$, (c) $200{ }^{\circ} \mathrm{C}$ and (d) $400{ }^{\circ} \mathrm{C}$.

As described above, pigment with high smoothness spreads well on the skin. The powder smoothness is also important for cosmetics [20]. Table 2 shows the smoothness of samples prepared at various $\mathrm{pH}$ and heating temperatures (hydrothermal time $8 \mathrm{~h}$ ). The values of MIU and MMD respectively represent the slipping resistance and roughness of powders. Sample powders were spread on the leather. Then a sensor was run over these powders. The values of MIU and MMD were calculated respectively from the power to move a sensor and the pitching of a sensor. The value of MIU decreases as a result of the heat treatment. Samples prepared at $\mathrm{pH}=7$ and 9 have the smaller values of
Table 2 Smoothness of samples prepared in various conditions

\begin{tabular}{ccccc}
\hline $\mathrm{pH}$ & $\begin{array}{c}\text { Hydrothermal } \\
\text { time (h) }\end{array}$ & $\begin{array}{c}\text { Temperature } \\
\left({ }^{\circ} \mathrm{C}\right)\end{array}$ & MIU & MMD \\
\hline 4 & 8 & 100 & 0.795 & 0.008 \\
4 & 12 & 100 & 0.767 & 0.007 \\
7 & 8 & R.T. & 0.425 & 0.006 \\
7 & 8 & 100 & 0.493 & 0.006 \\
7 & 8 & 200 & 0.304 & 0.006 \\
7 & 8 & 400 & 0.363 & 0.005 \\
7 & 12 & 100 & 0.437 & 0.005 \\
9 & 8 & 100 & 0.473 & 0.006 \\
9 & 12 & 100 & 0.413 & 0.006 \\
\hline
\end{tabular}

MIU than those at $\mathrm{pH}=4$. The value of MMD has little change by $\mathrm{pH}$, heating temperature and hydrothermal time. These values of MIU and MMD in samples prepared at $\mathrm{pH}=7$ and 9 are sufficiently small to be useful as a pigment for cosmetics.

\section{Conclusions}

Titanium phosphates were obtained from titanium chloride and sodium pyrophosphate solution. The obtained materials had a higher $\mathrm{Ti} / \mathrm{P}$ ratio than that in the preparation condition. All samples had a certain degree of amorphous phase. These titanium phosphates had less photo catalytic activity to protect the sebum on the skin. A large number of particles had smaller size than $100 \mu \mathrm{m}$ in samples prepared at $\mathrm{pH}=4$. Samples without heating and those heated at $100{ }^{\circ} \mathrm{C}$ showed high reflectance in the range of visible light. The slipping resistance of sample powders prepared at $\mathrm{pH}=7$ and 9 was sufficiently small to be useful as a pigment for cosmetics.

\section{Acknowledgements}

The authors are grateful to Dr. Takeshi Toyama, Nihon University, Japan, for smoothness measurements.

Open Access: This article is distributed under the terms of the Creative Commons Attribution License which permits any use, distribution, and reproduction in any medium, provided the original author(s) and the source are credited.

\section{References}

[1] Diebold U. The surface science of titanium dioxide. 
Surf Sci Rep 2003, 48: 53-229.

[2] Senzui M, Tamura T, Miura K, et al. Study on penetration of titanium dioxide $\left(\mathrm{TiO}_{2}\right)$ nanoparticles into intact and damaged skin in vitro. J Toxicol Sci 2010, 35: 107-113.

[3] Gamer AO, Leibold E, van Ravenzwaay B. The in vitro absorption of microfine zinc oxide and titanium dioxide through porcine skin. Toxicol in Vitro 2006, 20: 301-307.

[4] Onoda H, Nariai H, Moriwaki A, et al. Formation and catalytic characterization of various rare earth phosphates. J Mater Chem 2002, 12: 1754-1760.

[5] Onoda H, Ohta T, Tamaki J, et al. Decomposition of trifluoromethane over nickel pyrophosphate catalysts containing metal cation. Appl Catal A: Gen 2005, 288: 98-103.

[6] He Y, Zhao $\mathrm{M}$, Song $\mathrm{Y}$, et al. Effect of $\mathrm{Bi}^{3+}$ on fluorescence properties of $\mathrm{YPO}_{4}: \mathrm{Dy}^{3+}$ phosphors synthesized by a modified chemical co-precipitation method. J Lumin 2011, 131: 1144-1148.

[7] Onoda H, Matsui H, Tanaka I. Improvement of acid and base resistance of nickel phosphate pigment by the addition of lanthanum cation. Mat Sci Eng B 2007, 141: 28-33.

[8] Rao GV. Shashikala HD. Optical, dielectric and mechanical properties of silver nanoparticle embedded calcium phosphate glass. J Non-Cryst Solids 2014, 402: 204-209.

[9] Xu C, Lee J, Teja AS. Continuous hydrothermal synthesis of lithium iron phosphate particles in subcritical and supercritical water. J Supercrit Fluid 2008, 44: 92-97.

[10] Vani R, Girija EK, Elayaraja K, et al. Hydrotehrmal synthesis of porous triphasic hydroxyapatite/ $(\alpha$ and $\beta)$ tricalcium phosphate. J Mater Sci: Mater M 2009, 20: 43-48.
[11] Tomozawa M, Hiromoto S. Microstructure of hydroxyapatite- and octacalcium phosphate-coatings formed on magnesium by a hydrothermal treatment at various pH values. Acta Mater 2011, 59: 355-363.

[12] Onoda H, Yamaguchi T. Synthesis of titanium phosphate with additives and their powder properties for cosmetics. Mater Sci Appl 2012, 3: 18-23.

[13] Onoda H, Yamaguchi T, Takenaka A. Synthesis and pigmental properties of titanium phosphates with the addition of urea. Int J Cosmetic Sci 2012, 34: 86-90.

[14] Raynaud S, Champion E, Bernache-Assollant D, et al. Calcium phosphate apatites with variable $\mathrm{Ca} / \mathrm{P}$ atomic ratio I. Synthesis, characterisation and thermal stability of powders. Biomaterials 2002, 23: 1065-1072.

[15] Averbuch MT, Durif A. Topics in Phosphate Chemistry. Singapore: World Scientific Publishing, 1996.

[16] Onoda H, Ohta T, Kojima K. Mechanochemical reforming of nickel pyrophosphate. Mater Chem Phys 2006, 98: 363-367.

[17] Lucena-Conde F, Prat L. A new reagent for the colorimetric and spectrophotometric determination of phosphorus, arsenic and germanium. Anal Chim Acta 1957, 16: 473-479.

[18] Ramaswamy V, Jagtap NB, Vijayanand S, et al. Photocatalytic decomposition of methylene blue on nanocrystalline titania prepared by different methods. Mater Res Bull 2008, 43: 1145-1152.

[19] Du P, Bueno-López A, Verbaas M, et al. The effect of surface $\mathrm{OH}$-population on the photocatalytic activity of rare earth-doped $\mathrm{P} 25-\mathrm{TiO}_{2}$ in methylene blue degradation. $J$ Catal 2008, 260: 75-80.

[20] Cheng SY, Yuen CWM, Kan CW, et al. A comprehensive study of silicone-based cosmetic textile agent. Fiber Polym 2009, 10: 132-140. 